\title{
Spontaneous reporting of adverse events following pandemic influenza A (H1N1) immunization in a reference center in the State of São Paulo, Brazil
}

\author{
Danise Senna Oliveira ${ }^{[1]}$, Amanda Nazareth Lara ${ }^{[1]}$, André Machado Luiz ${ }^{[1]}$, \\ Karina Takesaki Miyaji ${ }^{[1]}$, Ana Marli Christovam Sartori ${ }^{[1]}$ and Marta Heloísa Lopes ${ }^{[1]}$
}

[1]. Centro de Referência para Imunobiológicos Especiais, Hospital das Clínicas, Faculdade de Medicina, Universidade de São Paulo, São Paulo, SP.

\begin{abstract}
Introduction: This paper describes adverse events (AEs) temporally associated to the pandemic influenza A (H1N1) vaccine observed in a reference center in São Paulo, Brazil, during a 2010 mass vaccination campaign. Methods: A retrospective study involving persons who sought medical care for AEs following influenza vaccination. Data were retrieved from medical records, vaccine AE notification forms, and a computerized system for immunobiological registration. Results: Sixty-six vaccinees sought medical care for AEs after immunization. The most frequent AEs were fever, headache, myalgia, and pain at the injection site. No serious AEs were reported. Conclusions: Few vaccinees spontaneously reported AEs to influenza A(H1N1) vaccine at this center.
\end{abstract}

Keywords: Pandemic influenza A (H1N1). Influenza vaccines. Adverse events following immunization.

In Brazil, during the 2009 season, pandemic influenza A (H1N1) was responsible for $93 \%$ of confirmed influenza cases, 44,544 cases of severe acute respiratory syndrome, and 2,051 deaths (mortality rate, $1.1 / 100,000)^{1}$.

In 2010, the Brazilian National Immunization Program conducted a large national vaccination campaign against pandemic influenza A (H1N1) that started on March 8 $\left(10^{\text {th }}\right.$ epidemiological week). Healthcare workers $(\mathrm{HCW})$ involved in the response to the pandemic were the first group to be vaccinated, followed by pregnant women, indigenous populations, individuals with chronic conditions, healthy children aged 6 to $<24$ months, healthy adults aged 20-29 years, seniors, and finally, healthy adults aged 30-39 years ${ }^{2}$. The monovalent vaccine against 2009 pandemic influenza A (A/California/7/2009 H1N1) was available throughout the campaign, while the trivalent influenza vaccine (A/ California/7/2009 (H1N1), A/Perth/16/2009 (H3N2), and B/ Brisbane/60/2008) only became available on April 24 for vaccinating seniors. The vaccination campaign was successful. Totally, 88 million people ( $46 \%$ of the Brazilian population) were vaccinated in 20 weeks (from March 8th to August 1st). It was the biggest vaccination campaign ever conducted in Brazil, exceeding the 67 million people vaccinated against rubella in $2008^{3}$. The Ministry of Health's goal of vaccinating at least $80 \%$ of the target population was surpassed for the whole target

Address to: Dra. Ana Marli Christovam Sartori. CRIE/HC/FM/USP. Av. Dr. Enéas de Carvalho Aguiar 155, PAMB/Bloco 8/4 ${ }^{\circ}$ andar, Cerqueira César, 05403-000 São Paulo, SP, Brasil.

Phone: 5511 2661-7517

e-mail: anasartori@gmail.com

Received 22 July 2011

Accepted 11 November 2011 population and particularly for persons with chronic conditions, children under 2 years, adults aged 20 to 29 years, HCW, and indigenous populations ${ }^{3}$. Nationwide, in 2010, there were 773 confirmed cases of 2,009 pandemic influenza A (H1N1) and 99 deaths, which occurred in epidemiological weeks 1 to 35 (from January $3^{\text {rd }}$ to September 4th, 2010). The peak incidence occurred in epidemiological week 10 (March 7-13, 2010), concomitant with the onset of the vaccination campaign, after which there was a continuous reduction in new cases ${ }^{4}$.

At the Hospital das Clínicas (HC), a large teaching hospital attached to the Faculdade de Medicina da Universidade de São Paulo (FMUSP), the vaccine was available in the Immunization Center (Centro de Referência de Imunobiológicos Especiais, CRIE-HC-FMUSP) throughout the season. In the hospital's main building (Instituto Central), during the vaccination campaign, the vaccine was also available for $\mathrm{HCW}$ in readily accessible places during working hours through mobile teams, as has been done since $2006^{5}$. In this center, 37,497 persons were vaccinated against pandemic influenza $A(H 1 N 1)$ in 2010, including 22,333 HCW and 13,217 individuals with chronic conditions. These numbers far exceeded the numbers of vaccinees in previous seasons. In 2008, 15,689 persons, of whom 7,733 were $\mathrm{HCW}$, were vaccinated in this center and 18,081 persons $(8,116 \mathrm{HCW})$ were vaccinated here in 2009 . Most persons $(25,838$ or $68.9 \%)$ received the monovalent H1N1 vaccine without adjuvant (21,943 doses from Instituto Butantan, 2,659 doses from Novartis, and 1,236 doses from Sanofi Pasteur); 7,548 (20.1\%) received monovalent H1N1 with adjuvant (GSK); and 4,111 (11\%) received the trivalent vaccine (Sanofi Pasteur).

Monitoring the safety of vaccines is an important aspect of a vaccination program. A passive surveillance system for adverse events following immunization (AEFI) has been in place in Brazil since the 1990s, and since 2005, reporting any 
AEFI is mandatory. In the CRIE-HC-FMUSP, all vaccinees were informed about possible adverse events (AEs) following influenza vaccination and advised to return if an AEFI occurred.

The aim of this study was to describe the AEs temporally associated with the pandemic influenza $\mathrm{A}(\mathrm{H} 1 \mathrm{~N} 1)$ vaccine that were spontaneously reported by vaccinees at the CRIE-HCFMUSP during the 2010 influenza vaccination campaign.

This is a descriptive retrospective study. All persons who sought medical care at the CRIE-HC-FMUSP reporting any AE temporally associated with the influenza vaccination during the 2010 season were included in the analysis. The data were collected from the medical records, AEFI notification forms, and the computerized system for immunobiological registration. Variables such as age, sex, reason for vaccine recommendation, the type of vaccine received (monovalent or trivalent), time between vaccination and the first symptoms, reported symptoms and signs, and whether the person had simultaneously received other vaccines were analyzed.

The study was approved by the Research Ethics Committee of the Hospital das Clínicas da FMUSP (protocol n 0673/10).

During the 2010 season, 66 persons sought medical care at the CRIE-HC-FMUSP due to AEs temporally associated with the vaccination against influenza. Their ages ranged from 8 to 68 years; only 1 of the 66 individuals was a child. Most were women $(87.9 \%)$ and $\mathrm{HCW}(80.3 \%)$ and had received the monovalent vaccine without adjuvant (73.4\%). Only 1 person had received the trivalent influenza vaccine. The average period of time between vaccination and the onset of symptoms was $48 \mathrm{~h}$, and the median was $24 \mathrm{~h}$. The longest time between vaccination and the symptoms was 51 days (Table 1).

Systemic AEs following influenza A immunization were reported by $55(83.3 \%)$ vaccinees, most frequently fever, headache, and myalgia (Figure 1). Other less frequent symptoms (reported only once each) were chills, anxiety, bitter mouth, pain and cramps in the lower limbs, eyelid swelling, skin thickening, skin lesion (poorly described in the medical record), painful cervical lymph node, nasal obstruction, red eyes, and Raynaud's phenomenon in a person who had previously presented this symptom.

Eighteen (27.2\%) persons reported an $\mathrm{AE}$ at the injection site, most frequently, local pain. Other local symptoms, reported only once each, were injection site hematoma and vesicles around the injection site that suggested herpes zoster. Six (9\%) persons reported hypersensitivity reactions (Figure 1).

Three persons had received another vaccine simultaneously with the influenza vaccine: tetanus and diphtheria toxoids (1), yellow fever vaccine (1), and Measles-Mumps-Rubella vaccine (1). The person who had received both influenza and yellow fever vaccines presented with fever, headache, myalgia, and cramps in the lower limbs beginning 2 days after vaccination. Although fever, headache, and myalgia may occur after yellow fever vaccination, this vaccinee associated her symptoms with the influenza vaccine.

Most of the AEs temporally associated to the vaccination against pandemic Influenza A (H1N1) were reported at the beginning of the immunization campaign: $62.1 \%$ of all medical
TABLE 1 - Demographic characteristics, type of vaccine received, and time between vaccination and first symptoms for 66 persons who spontaneously sought medical care due to adverse events following pandemic influenza A (H1N1) immunization in a reference center in São Paulo, Brazil, 2010.

\begin{tabular}{|c|c|c|}
\hline Characteristic & Numbe & Percentage \\
\hline \multicolumn{3}{|l|}{ Sex } \\
\hline female & 58 & 87.9 \\
\hline male & 8 & 12.1 \\
\hline \multicolumn{3}{|l|}{ Age (years)* } \\
\hline range & \multicolumn{2}{|c|}{$8-68$} \\
\hline mean & \multicolumn{2}{|c|}{38} \\
\hline median & \multicolumn{2}{|c|}{55} \\
\hline \multicolumn{3}{|l|}{ Target group of vaccination } \\
\hline healthcare worker & 53 & 80.3 \\
\hline chronic condition & 11 & 16.7 \\
\hline not reported & 2 & 3.0 \\
\hline \multicolumn{3}{|l|}{ Vaccine } \\
\hline monovalent & 64 & 97.0 \\
\hline without adjuvant & 47 & 73.4 \\
\hline with adjuvant & 17 & 26.6 \\
\hline trivalent without adjuvant & 1 & 1.5 \\
\hline not reported & 1 & 1.5 \\
\hline
\end{tabular}

Time between vaccination and symptoms

mean (hours)

median (hours)

24

$$
\leq 24 \mathrm{~h}
$$

20

30.3

24-48h

26

39.4

48-72h

8

12.1

$>72 \mathrm{~h}$

9

13.6

not reported

3

visits occurred in the first 2 weeks of the campaign and $87.8 \%$, in the first 5 weeks (Figure 2).

From January 2 to October 31, 2010, the CRIE-HC-FMUSP team administered 36,008 doses of immunobiologicals other than influenza vaccine, which resulted in 15 medical visits due to AEs temporally associated with those immunobiologicals.

At the CRIE-HC-FMUSP, the pandemic influenza A(H1N1) vaccine was well tolerated with few vaccinees spontaneously reporting systemic or local AEs.

Healthcare workers and seniors were the majority of the target population served by the CRIE-HC-FMUSP for the influenza immunization, which should explain the median age of 55 years of the persons who sought medical care for AEs temporally associated with the pandemic influenza vaccination. Additionally, HCW working in the Hospital das Clínicas have easy access to the CRIE-HC-FMUSP, and the finding that most 


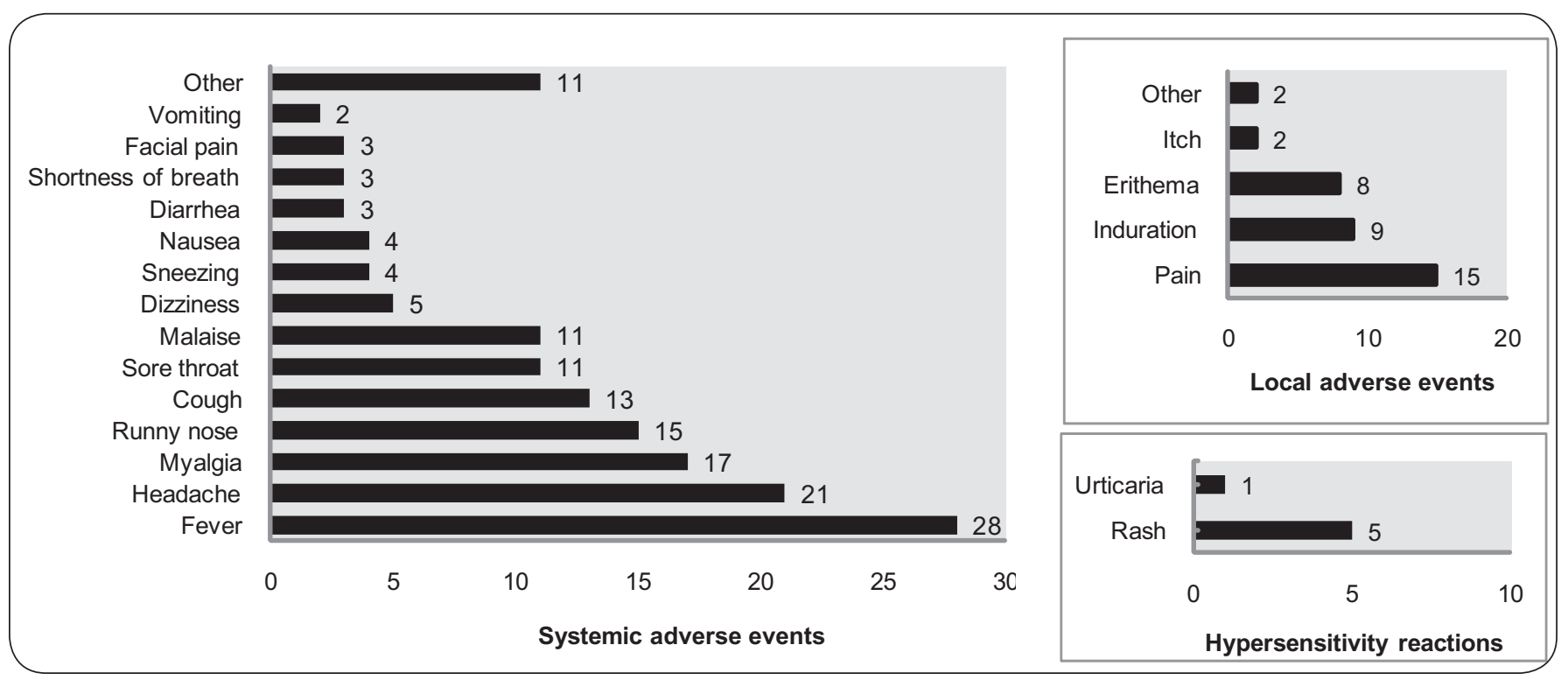

FIGURE 1 - Number of spontaneously reported adverse events following pandemic influenza A (H1N1) immunization.

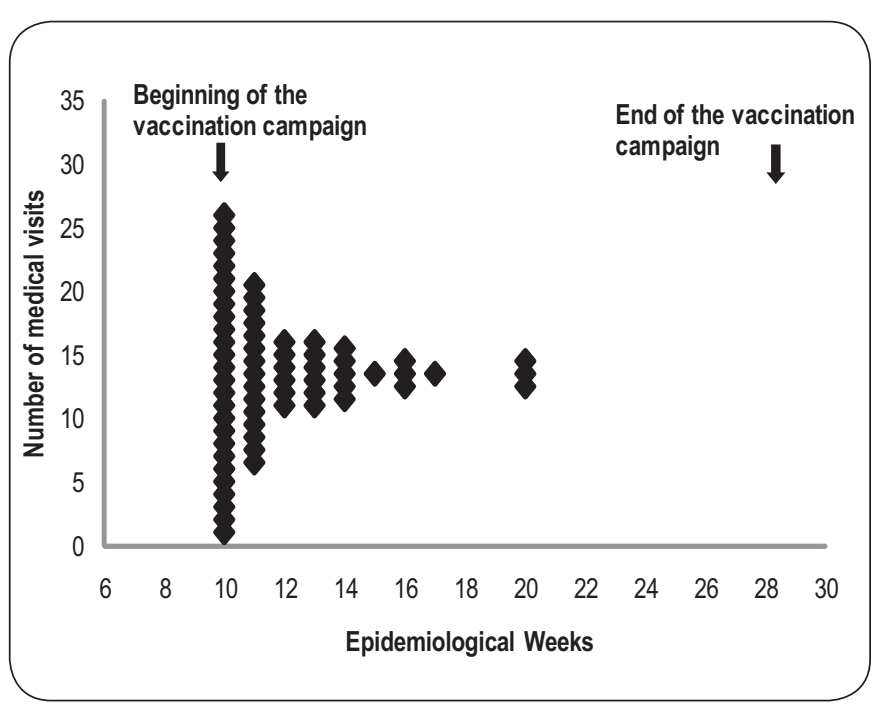

FIGURE 2 - Distribution of medical visits for adverse events following pandemic influenza A (H1N1) immunization.

persons who sought care due to AEs were women may have been partly due to the gender distribution of $\mathrm{HCW}$ at the hospital ${ }^{6}$ and possibly due to the general tendency of women to access healthcare services more often than men?

Systemic AEs were more frequent than local AEs, which is similar to what has been observed in other studies ${ }^{8-10}$. Systemic AEs that were difficult to measure, such as headache, myalgia, and unmeasured fever, were reported most frequently. AEs that were difficult to measure, such as pain, also predominated at the injection site. No serious AE was reported. The frequency and severity of the AEs observed in this study were similar to those reported following the seasonal influenza vaccine in previous seasons, led by pain and tenderness at the injection site and followed by systemic AEs such as headache, malaise, and myalgia in the first 4 days after immunization ${ }^{11}$.
Our findings are similar to those of a study conducted in Australia, in which a vaccine similar to the one used in the Brazilian mass vaccination campaign (inactivated monovalent influenza A (H1N1) vaccine, without adjuvant, with $15 \mathrm{mcg}$ of hemagglutinin and thimerosal) was used. The main AEs observed in the Australian study were pain and tenderness at the injection site, with systemic AEs including headache, malaise, and myalgia $^{12}$. Other studies conducted in Denmark, Italy, China, and Germany in order to evaluate different vaccines with or without adjuvant supported the safety of the 2009 pandemic influenza A (H1N1) vaccine. Most of AEs observed in those studies were mild $^{8-10,13}$. It should be pointed out that fever after influenza A (H1N1) immunization was more frequently observed in this study (42\%) than in those of others ${ }^{9,13}$, possibly because in this study, any report of fever, even if unmeasured, was recorded. Fever and febrile seizures were reported in children under 5 following immunization with an inactivated influenza vaccine without adjuvant or thimerosal (Fluvax) in Australia, which led to discontinuation of the use of all 2010 seasonal influenza vaccines in healthy children under 5 in Australia ${ }^{14}$. In China, 89.6 million people were vaccinated with a different influenza $A(H 1 N 1)$ split virion vaccine, without adjuvant, that was produced domestically. Fever was the most frequent AE reported to the passive AEFI surveillance database (39.1 cases/ 1 million doses administered $)^{10}$, and most AEs were recorded at the beginning of the vaccination campaign, particularly in the first 5 weeks ${ }^{10}$.

Greater frequency of medical visits due to AEs at the beginning of the vaccination campaign, as well as a greater number of AEs temporally associated with the pandemic influenza A (H1N1) vaccination when compared with other immunobiologicals, was expected. There was huge publicity for the pandemic influenza A (H1N1) vaccine, which raised awareness for perception and reporting of AEFI. Although the pandemic influenza vaccines had the same manufacturing and approval processes used for seasonal influenza vaccines and thus 
were expected to present the same safety profile as the seasonal vaccines ${ }^{15}$, people saw them as new vaccines. Vaccine safety is a great concern in any mass vaccination campaign, during which huge numbers of persons are immunized in a short period of time, and this might uncover more AEs associated with the vaccine, even if rare. Furthermore, HCWs had been encouraged to report any AE following the influenza vaccine ${ }^{15}$.

We believe vaccination is the most effective way to prevent influenza. Public confidence in a vaccination program is a key factor for a successful program. Answers to public concerns regarding vaccine safety must be provided to help secure adherence of the target population to the program and achieve high vaccination coverage. Surveillance of vaccine safety when a vaccine is used for routine immunization of specific populations is critical. Although limited, passive surveillance of AEFI allows detection of unrecognized AEs, detection of vaccine lots associated with unusual numbers and types of AEs, and monitoring of safety of newly licensed vaccines ${ }^{15}$.

\section{ACKNOWLEDGMENTS}

We thank the staff of the CRIE- HC-FMUSP for their extensive hard work and encouragement during the huge vaccination 2010 campaign against pandemic influenza A (H1N1). The authors thank Dr. Anna Sara Shafferman Levin for the manuscript review.

\section{CONFLICT OF INTEREST}

The authors declare that there is no conflict of interest.

\section{REFERENCES}

1. Ministério da Saúde. Boletim Eletrônico Epidemiológico. Influenza pandêmica (H1N1) 2009 - Análise da Situação Epidemiológica e da Resposta no ano de 2009. Ano 10, n² 2. Brasília: Secretaria de Vigilância em Saúde; 2010.

2. Ministério da Saúde. Secretaria de Vigilância em Saúde.Estratégia de Vacinação contra o Vírus de Influenza A(H1N1) 2009 Pandêmico e Sazonal. Nota Técnica n ${ }^{\circ}$ 011. Brasília: Departamento de Vigilância Epidemiológica; 2010.
3. Ministério da Saúde. Informe Técnico Quinzenal de Influenza. Influenza Pandêmica (H1N1) 2009 - Monitoramento da Síndrome Respiratória Aguda Grave (SRAG) em Hospitalizados. Edição nº 7. Brasília: Secretaria de Vigilância em Saúde; 2010.

4. Ministério da Saúde. Informe Técnico Quinzenal de Influenza. Influenza Pandêmica (H1N1) 2009 - Monitoramento da Síndrome Respiratória Aguda Grave em Hospitalizados. Edição n ${ }^{0}$ 9. Brasília: Secretaria de Vigilância em Saúde; 2010.

5. Lopes MH, Sartori AM, Mascheretti M, Chaves TS, Andreoli RM, Basso M, et al. Intervention to increase influenza vaccination rates among healthcare workers in a tertiary teaching hospital in Brazil. Infect Control Hosp Epidemiol 2008; 29:285-286.

6. Lopes MH, Mascheretti M, Franco MM, Vasconcelos R, Gutierrez EB. Occurrence of early adverse events after vaccination against influenza at a Brazilian reference center. Clinics (Sao Paulo) 2008; 63:21-26.

7. Mendoza-Sassi R, Béria JU, Barros AJ. Outpatient health service utilization and associated factors: a population-based study. Rev Saude Publica 2003; 37: 372-378.

8. Folkenberg M, Callreus T, Svanstrom H, Valentiner-Branth P, Hviid A. Spontaneous reporting of adverse events following immunisation against pandemic influenza in Denmark November 2009-March 2010. Vaccine 2011; 29:1180-1184.

9. Cristiani C, Tuccori M, Pepe P, Sarteschi A, Maddalo F, Simonini G, et al. Safety of MF-59 adjuvanted vaccine for pandemic influenza: results of the vaccination campaign in an Italian health district. Vaccine 2011; 29:3443-3448.

10. Liang XF, Li L, Liu DW, Li KL, Wu WD, Zhu BP, et al. Safety of influenza A $(\mathrm{H} 1 \mathrm{~N} 1)$ vaccine in postmarketing surveillance in China. N Engl J Med 2011; 364:638-647.

11. Donalisio MR, Ramalheira RM, Cordeiro R. Adverse reactions to influenza vaccine in the elderly, Campinas District, SP, 2000. Rev Soc Bras Med Trop 2003; 36:467-471.

12. Greenberg ME, Lai MH, Hartel GF, Wichems CH, Gittleson C, Bennet J, et al. Response to a monovalent 2009 influenza A (H1N1) vaccine. N Engl J Med 2009; 25:2405-2413.

13. Loebermann M, Anders G, Brestrich G, Fritzsche C, Klammt S, Borso $\mathrm{D}$, et al. Safety and immunogenicity of a trivalent single dose seasonal influenza vaccine containing pandemic $\mathrm{A}(\mathrm{H} 1 \mathrm{~N} 1)$ antigen in younger and elderly subjects: a phase III open-label single-arm study. Vaccine 2011; 29:1228-1234.

14. World Health Organization (WHO). Febrile Seizures Following Seasonal Influenza Vaccination in Australia. Wkly Epidemiol Rec 2010; 285-292.

15. Vellozzi C, Broder KR, Haber P, Guh A, Nguyen M, Cano M, et al. Adverse events following influenza A (H1N1) 2009 monovalent vaccines reported to the Vaccine Adverse Event Reporting System, United States, October 1, 2009-January 31, 2010. Vaccine 2010; 28:7248-7255. 